\title{
The Development and Implementation of a Comprehensive Seismic Risk Management Plan at Agnico-Eagle's LaRonde Mine
}

\author{
F. Mercier-Langevin Agnico-Eagle Mines Ltd, LaRonde Division, Canada \\ M.R. Hudyma Itasca Consulting Canada Inc., Canada
}

\begin{abstract}
The LaRonde mine is characterised by a foliated, highly deformable rock mass. Previous work has documented the influence of foliation on rock mass behaviour and the resulting deformation observed in the vicinity of excavations. However, as the spacing of the foliation planes increases within the mine there is an observed transition in behaviour, from high deformation to seismogenic. Consequently, significant levels of seismicity are recorded in areas of competent rock. These can occasionally be accompanied by rockburst occurrences.

Since the introduction of a mine-wide seismic system in 2003, seismic data have been employed along with field observations in order to develop site-specific strategies to address seismic risk as it evolves in the mine. The resulting mitigation measures have been refined on a continuous basis in order to minimise workforce exposure to seismic risk. Currently, seismic risk management is an integral part of mining at LaRonde.

Recently the mine went a step beyond "traditional" seismic risk management methods by developing a formal "Seismic Risk Management Plan". This document serves as a compilation of rockbursting and seismicity issues at LaRonde and how these issues are being addressed by mine management. The resulting plan has been constructed in such a way that its key components and their application can be verified by quantifiable internal and external audits.
\end{abstract}

\section{Introduction}

Agnico-Eagle's flagship LaRonde mine is exploiting the largest gold deposit in Canada. It is located in the Abitibi Region of north-western Quebec, approximately $650 \mathrm{~km}$ northwest of Montreal. The 2250 metre Penna Shaft, which is the deepest single-lift shaft in the Western Hemisphere, is used to hoist LaRonde's ore production of approximately $7300 \mathrm{t}$ per day. Current mining operations are taking place at over 2300 metres below surface and expansion phases are planned to further expand mining activities to depths exceeding 3100 metres. Located near the village of Preissac in Northern Quebec, the LaRonde mine has been in operation since 1988. Over 600 employees are operating the complex. Production is ongoing between level 98 (980 metres below surface) and level 233 (2330 metres below surface).

Figure 1 presents a longitudinal view of the LaRonde orebody. As of 2006, reserves at LaRonde and LaRonde II total over 35 million $t$ of ore, for over 5.1 million ounces of gold (Agnico-Eagle, 2007). The LaRonde orebody remains open at depth, with reserves as deep as $3110 \mathrm{~m}$ below surface. At the planned rate, operations are expected to continue beyond 2020.

This paper focuses on seismicity at the mine, and particularly on damaging events, commonly known as rockbursts. A significant number of these damaging events have occurred at the mine since the commissioning of the Penna Shaft and over time, as additional knowledge was gained, various seismic risk mitigation measures have been put in place. Recently it was felt that it was time to go beyond traditional seismic risk management methods. Thus, a formal, auditable "Seismic Risk Management Plan" was developed. This document is meant to serve as a compilation of the understanding of the rockbursting and seismicity issues at the mine and how these issues are being addressed by mine management. LaRonde is one of the first mines in the world to develop such a proactive and transparent tool, demonstrating its commitment to safety. 


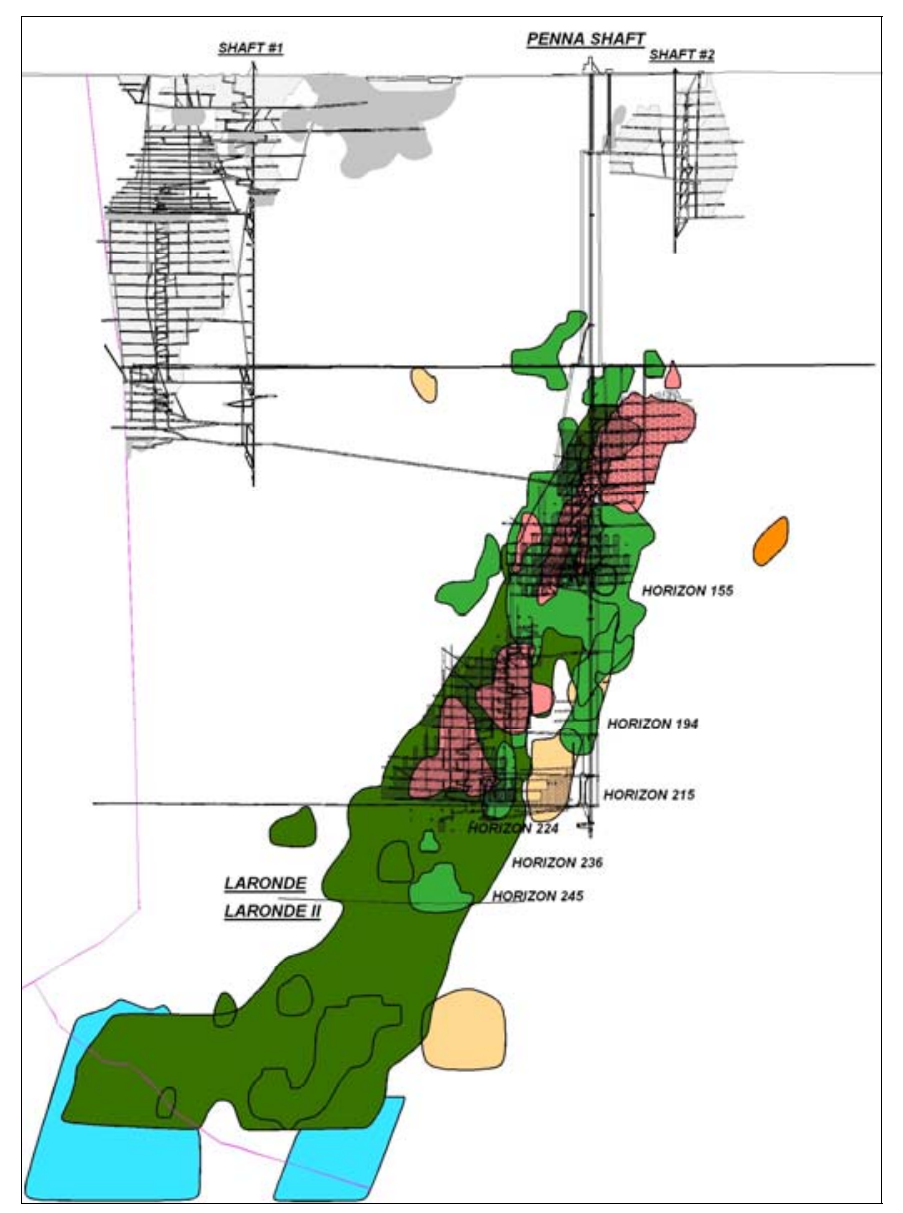

Figure 1 Longitudinal view of the LaRonde orebody

\section{History of seismicity and rockbursting at LaRonde}

Seismicity has been a part of day to day life at the Penna Shaft since the early stages of mining in the upper mine. This section presents the events that significantly changed the way the mine dealt with seismic risk, and eventually lead to the development of the current Seismic Risk Management Plan.

\subsection{November 27th 2002 rockburst}

The first damaging event at the mine occurred after close to two years of operation, at 7:31 pm on November 27 th 2002, when a large seismic event was felt underground and on surface. Upon inspection of the various levels, damage was found on levels 149 and 152 (the sill level of the upper stoping pyramid).

On level 149, the damage consisted mostly of rock ejection from the lower portion of the walls in the haulage drift (Figure 2). Significant floor heave was also observed in the same location. On level 152, the back of the intersection between the cross-cut and the haulage drift had collapsed. The event was recorded by the Geological Survey of Canada, which estimated its magnitude at 2.7 on the Nuttli scale. 


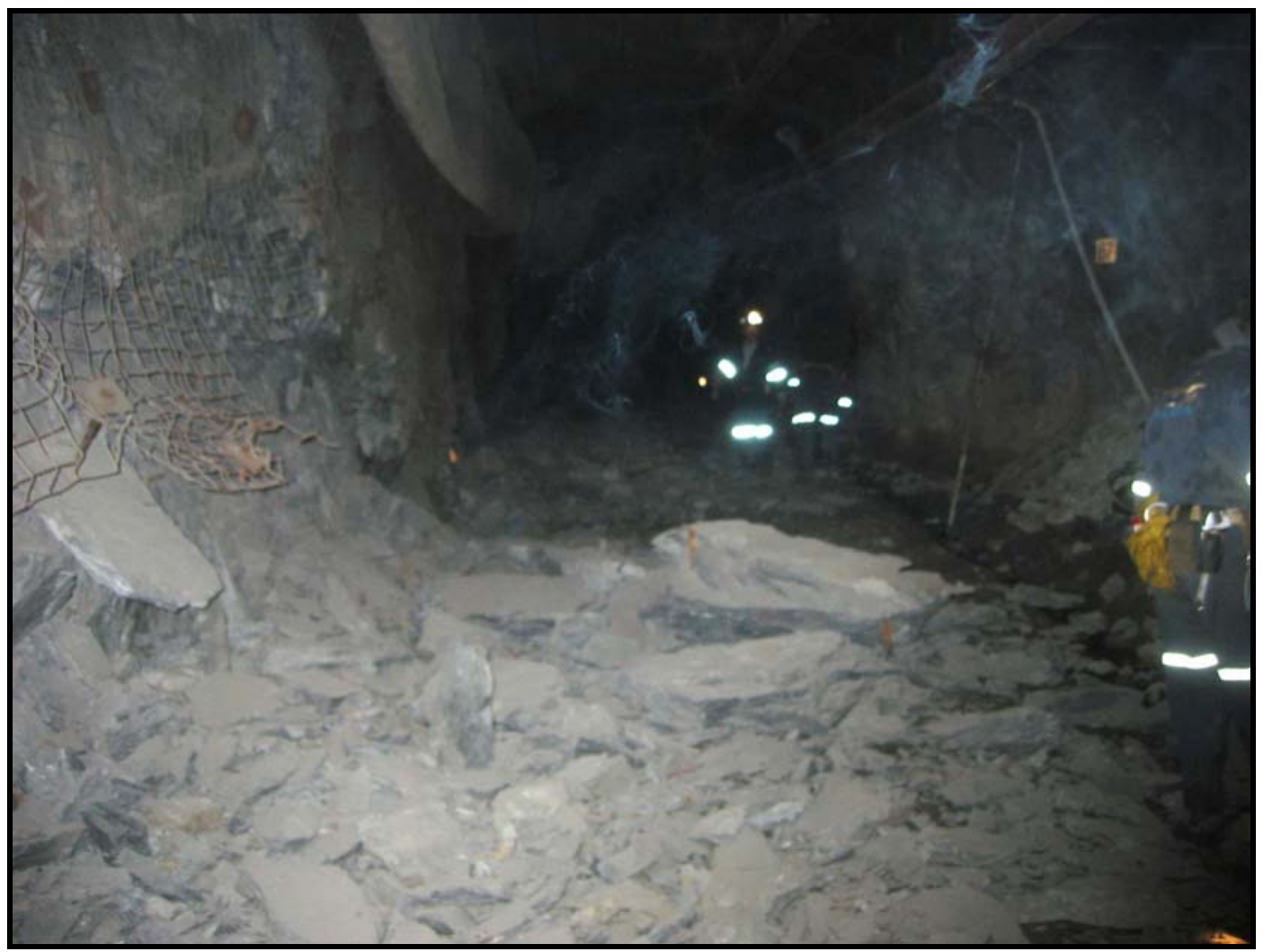

Figure 2 Ejected material in 149-20W haulage drift following the November 27th 2002 event (lower part of North wall ejected)

Although the workforce was not in the vicinity at the time of the event, it was clear that microseismic monitoring was needed at the mine if it was to keep operating in a safe manner. A portable microseismic system was installed a few days afterwards, as a temporary measure until a minewide seismic monitoring system could be installed. A 64-channel, mine-wide ESG Hyperion system was commissioned in August 2003.

Since this first damaging event, several more rockbursts have occurred at the mine, with a noticeable acceleration in 2005 , as the extraction ratio increased and individual mining horizons began merging together. However, as additional knowledge was gained and new procedures were introduced, the actual risk to people and the potential effects of seismicity on production were both considerably reduced in the same period.

\subsection{April 1st 2006 rockburst}

The largest rockburst to date occurred at 5:45 pm on April 1st 2006 (Mercier-Langevin, 2006). The mass blast of the 170-20-52 stope triggered a $\mathrm{M}_{\mathrm{N}}=2.7$ event ( 4 seconds after the blast), which caused extensive damage on three levels (in excess of $800 \mathrm{t}$ displaced). The event occurred in the floor of the EP-164-20-W haulage drift. Figure 3 shows the extent of the damage in this drift, which was hit the hardest.

The event occurred at blast time when no one was underground and thus resulted in no injury and caused no damage to equipment. Furthermore, most of the damage was confined to an area proactively designated noentry. However, mine management treated this incident as if it had resulted in losses, and launched a fullscale investigation into its underlying causes and the procedural response at the mine. The objective of the investigation was to try to learn from this event, to further improve the capability of the mine to deal with major rockbursts and develop a proactive plan towards mitigating seismic risk. Consultants were invited to take part in this investigation as external reviewers (Andrieux and Hadjigeorgiou, 2006). 


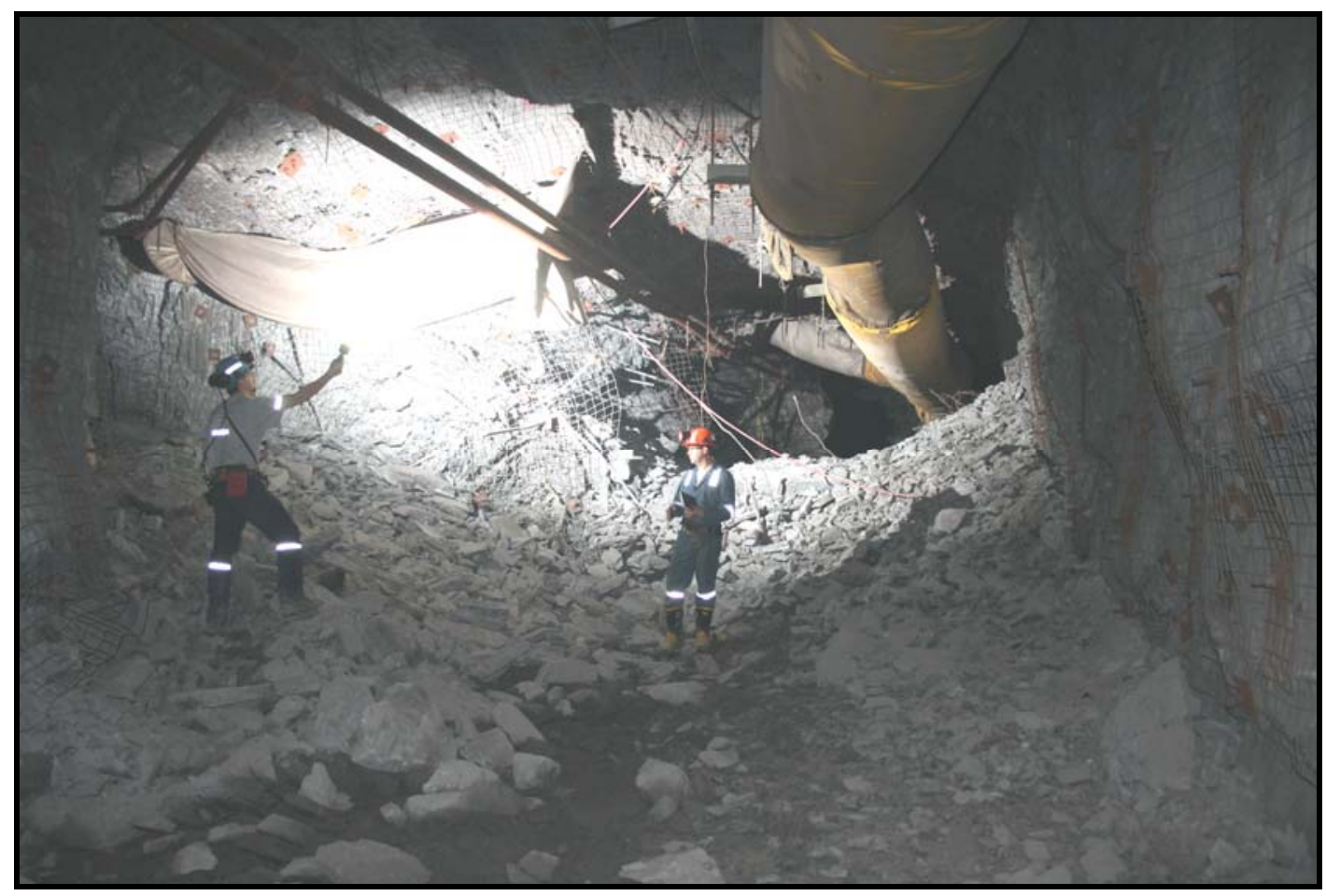

\section{Figure 3 Damage in haulage drift EP-164-20W following the April 1st event (south pillar ejected)}

During the investigation, the mine was commended by the auditors for putting in place a number of procedures pertaining to seismic risk management and for updating them on a regular basis. However, it was also noted that it was difficult for an external observer to quickly locate this information, and that there was no clear indication that the information provided reflected the current standard or was superseded by a more recent version.

\subsection{December 11th 2006 and January 11 th 2007 rockbursts}

At 1:47 am on December 11th 2006, a large event was felt underground and located on 224 level by the microseismic system $\left(\mathrm{M}_{\mathrm{N}}=1.5\right)$. The damage associated with the event was minor, with less than $5 \mathrm{t}$ displaced, mostly contained by support. However, almost exactly one month later (at 6:27 pm on January $\left.11^{\text {th }}, 2007\right)$, a second event $\left(\mathrm{M}_{\mathrm{N}}=1.9\right)$ occurred in the same location. This second, larger event resulted in significant damage to the nearby haulage drift EP-224-47E (approximately $50 \mathrm{t}$ were displaced, Figure 4).

Although these events still did not result in any injury and were relatively minor in terms of damage, they still raised a number of concerns, as they did not fit any previously identified seismicity and rockbursting patterns at the mine. An external consultant was asked to review the occurrence of these two events in order to provide additional insight into the possible mechanisms behind these events and suggest mitigation measures.

One of the conclusions of this review was that, throughout its history, LaRonde had taken a number of proactive steps to manage seismic risk and reduce the likelihood of rockburst damage. Consequently, most of the aspects of seismic risk management were partially or wholly addressed in separate LaRonde procedures and documents. It was recommended that all of this information should be assembled into a single, auditable document (Hudyma, 2007). 


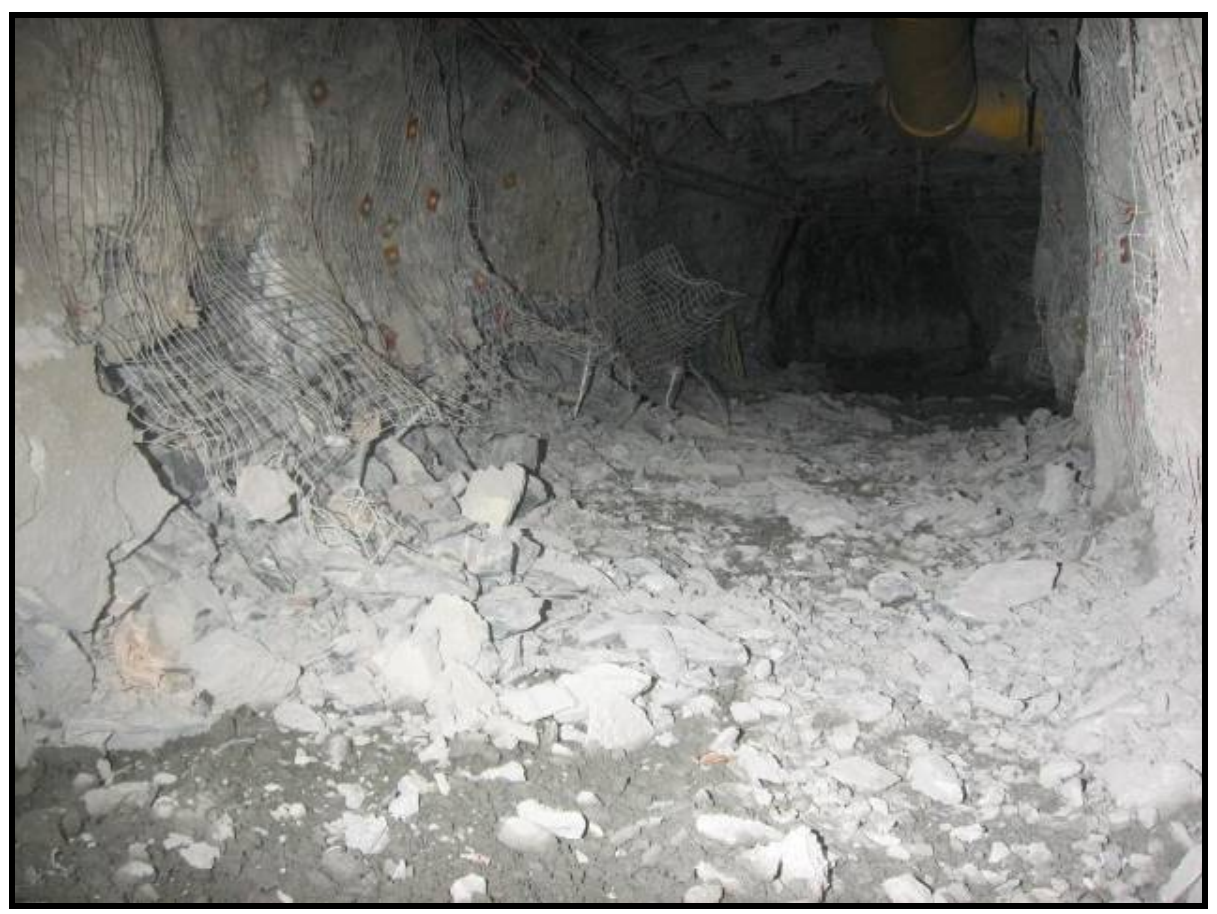

\section{Figure 4 Damage in haulage drift EP-224-47E following the January 11th 2007 event (lower part of North wall ejected)}

\section{Seismic risk management plan}

The LaRonde Seismic Risk Management Plan (SRMP) was designed to provide a complete and accurate history of past seismicity and mitigation measures implemented throughout the life of the mine. This document was also to serve as a tool for external audits. In that respect, it had to be a transparent document centralising all the procedures, mine design considerations, communication tools and workplace practice changes pertaining to seismicity at the mine. It would also ensure that this knowledge was readily available to any new staff or management personnel at the mine, and that knowledge would remain at the mine should any staff member leave.

The following sections of this paper follow the layout of the document, the purpose of each section, and a brief description of the LaRonde SRMP.

\subsection{General considerations}

The SRMP starts with a general description of the document, outlining the objectives of the SRMP and its contents. A list of all key personnel that are to be involved in the approval process is also provided, as well as a list of all key personnel to whom the final document is distributed. This section also states the frequency at which the document needs to be updated, and who is responsible for this update.

\subsection{Seismic monitoring tools}

One of the key components in managing seismic risk is reliable monitoring of all significant mining-induced seismicity at the mine. Through seismic monitoring, the mechanisms and causes of seismicity can be investigated, leading to mining method and mining practice changes that allow better management of the risks associated with large seismic events. As such, it is deemed particularly important that the SRMP contain a description of the seismic monitoring tools, as well as their dynamic range and known limitations.

The ESG microseismic monitoring system at LaRonde currently covers the mine from the 128 Level to the 233 Level (1280 to 2330 metres below surface). This system can monitor up to 72 channels, and currently has 51 uniaxial accelerometers and 6 triaxial accelerometers. The uniaxial sensors provide a high sensitivity 
with all events greater than local magnitude -2 being recorded. The accuracy of location for most events is believed to be within 10 metres of the seismic source.

The triaxial sensors provide an estimate of seismic source parameters, of which local magnitude is the most commonly used. At LaRonde, the ESG seismic system can reliably assess local magnitude between -3 and about 0 . Comparing the largest of these events to magnitude assessed by the Geological Survey of Canada gives an approximate relation of:

$$
\mathrm{M}_{\mathrm{N}} \sim \mathrm{M}_{\mathrm{L}}+1.5
$$

It is important to note that seismic event and rockburst prediction are not the goals of seismic monitoring at LaRonde. The objective of seismic monitoring is to proactively identify the rock mass conditions, stress conditions and mining influences conducive to the occurrence of large seismic events.

It has been found that seismic events greater than local magnitude 0, may saturate the ESG seismic system, leading to an underestimation of event magnitude. To alleviate this, a surface mounted triaxial geophone was installed in 2006. This sensor is located approximately two kilometres from LaRonde and gives magnitude estimates for events between Nuttli magnitude +0.5 to about Nuttli magnitude +3.5 . The addition of this surface sensor has helped define the limits of the microseismic system

\subsection{Rockburst history}

More than 30,000 seismic events have been recorded at LaRonde since 2003, however, only 19 of these events have resulted in observed damage in the mine. As a general rule, the larger the event and the closer it is to excavations, the greater the potential for damage.

\subsubsection{Summary of damaging events - rockburst database}

A rockburst database has been built, containing the details of all damaging events recorded at the mine. It is greatly beneficial that a database of damaging events be compiled and kept up to date since these events pose the greatest risk to mine workers, infrastructure and production. The purpose of the database is to provide a means of identifying trends in rockburst damage, particularly with respect to the location and timing of damaging events. The database will also ensure continuity of this key information to future rock mechanics staff at the mine. The LaRonde database of damaging events includes the following elements:

- Event location and region of the event.

- Local and Nuttli magnitude.

- Inferred seismic source mechanism of the event.

- Location compared to the failure front (discussed in Section 3.3.2).

- Most recent stope blast and the distance to that blast.

- Tonnes displaced and tonnes contained by the ground support system.

- Distance from the seismic event location to the damage.

- Information regarding the size and orientation of the development that was damaged.

- Photos of the various damage locations.

- Ground support systems in place in the damaged areas.

- Inferred damage mechanism of the event.

The exercise of compiling and analysing that database has been invaluable in understanding damaging seismic events at LaRonde.

\subsubsection{Ground conditions, stress conditions and configurations conducive to rockbursts}

This section of the SRMP lists specific ground conditions that personnel should be aware of when developing new zones, as they have been found to be associated with higher levels of seismicity. 
The LaRonde orebody is a series of disseminated and massive sulphide orebodies contained within strongly foliated felsic tuff. Experience at LaRonde has shown that some local rock mass conditions are more associated with seismicity, including: a wider spacing on the foliation, silicification with quartz veins and the absence of weaker alteration zones.

Rock mechanics investigations have identified a halo of seismicity around the mine stopes that relates to a post-peak stress failure front in the mine (Hudyma and Brummer, 2006). The vast majority of the significant seismic events at LaRonde in the last 4 years have occurred in this stress failure zone immediately following final stope blasts in primary and secondary stopes. The events generally occur within one level of the stope blast and within 100 metres of the blast.

\subsubsection{Specific areas of the mine more prone to seismicity and rockbursting}

This section identifies specific areas of the mine that have displayed higher levels of seismicity and a higher risk of rockbursting.

There are five main, high hazard regions at LaRonde, which are more prone to significant and large seismic events (local magnitude $\geq-1$, or approximate Nuttli magnitude $\geq+0.5$ ). Figure 5 shows these five areas. Regions 1, 2 and 3 are sill pillar mining areas in which mining fronts are converging. Region 4 is a footwall stringer, being mined with a pillarless retreat sequence. Region 5 is a mine abutment.

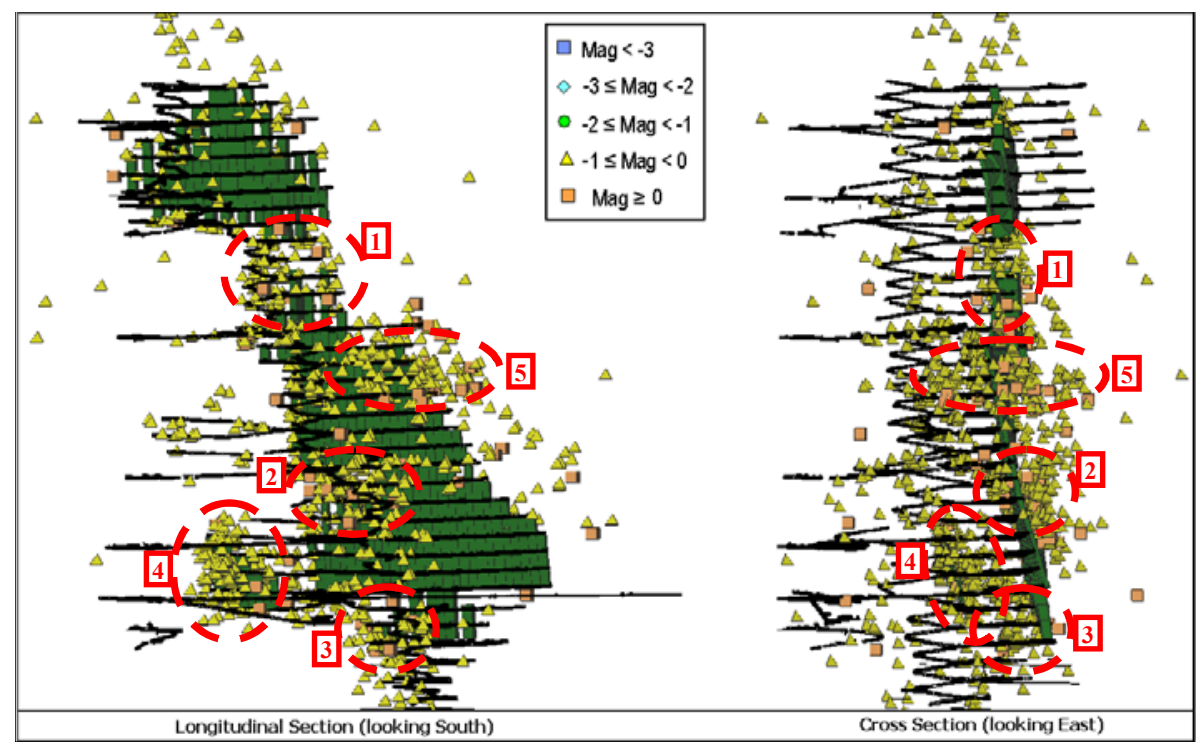

Figure 5 Location of the significant and large events at LaRonde (local magnitude $\geq-1$ )

\subsection{Seismic risk management tools}

It is possible to qualitatively or quantitatively assess seismic risk in underground mining using the following three component approach (Heal et al., 2006):

$\begin{gathered}\text { Seismic } \\ \text { Risk }\end{gathered}=\begin{gathered}\text { Seismic } \\ \text { Hazard }\end{gathered} \quad \begin{gathered}\text { Excavation } \\ \text { Vulnerability }\end{gathered} \times \begin{gathered}\text { Workforce } \\ \text { Exposure }\end{gathered}$

A reduction of any one of these factors results in a direct reduction in seismic risk to people and equipment. The following sections describe all the tools used at LaRonde in order to minimise seismic risk.

Seismic hazard is an intrinsic property of the rock mass. To a degree, optimum mine sequencing and mining practices can reduce seismic hazard. However, seismic hazard cannot be completely eliminated. The main technique used at the mine for managing seismic hazard is to recognise and try to avoid locations and times when seismic hazard is highest (Section 3.4.1).

Excavation vulnerability can be addressed in a variety of ways, namely in optimising the size, shape or orientation of development with regards to seismic risk (Section 3.4.2) or in adding dynamic-resistant support to excavations (Section 3.4.3). 
Exposure is also a factor over which we can exercise some control. Exclusion zones can be implemented (Section 3.4.4), workplace practices can be modified (Section 3.4.5) and training can be provided, so that people better understand their working environment and how to minimise their exposure to active ground conditions (Section 3.4.6).

\subsubsection{Avoid areas of high seismic hazard}

The highest hazard areas of the mine are sill pillars (Areas 1, 2 and 3 in Figure 5) and some of the stope abutments (Areas 4 and 5 in Figure 5). Historically most of the large and damaging events have occurred in these areas. These events almost always occur within 4 days of final stope blasts in primary stopes and to a lesser degree following secondary stopes. Mine development is carefully considered and optimum stope sequencing is paramount to successful mining in these areas. It is recognised that even when mining is successful, upgraded ground support is likely required.

\subsubsection{Modifications to excavation design}

The rockburst database at LaRonde clearly shows that past damage has generally occurred in footwall development, near the orebody, particularly in wider excavations. The most severe damage has also occurred in excavations parallel to the East-West foliation and orebody.

A number of modifications have been made to development design to minimise the potential for seismic related damage. Development dimensions are kept as small as possible and the number of intersections near the orebody minimised. Four-way intersections that lead to greater spans were eliminated in the lower part of the mine. In areas prone to seismicity, development at an angle to the foliation is the preferred configuration.

\subsubsection{Ground support}

In high hazard areas potentially prone to rockburst damage, dynamic resistant ground support elements are used to minimise potential rock mass damage.

Modified conebolts were introduced at the mine in 2003 to provide additional energy absorption capacity to the ground support system. These bolts were primarily used in the walls of footwall development, on a $1.5 \times 1.5 \mathrm{~m}$ pattern, in conjunction with 0 gauge ( $7 \mathrm{~mm}$ thick) mesh straps. However, in April 2006, the use of modified conebolts was discontinued when it was repeatedly observed that a shearing rock mass failure mechanism in development walls was causing pinching and failure of the bolts (Simser et al., 2006).

It was concluded that conebolts are a practical dynamic ground support element, but only in locations where wall deformation is minimal.

In 2007, a hybrid bolt was introduced as the standard ground reinforcement element following good performance in minimising rock mass damage in the January 11, 2007 rockburst (Mercier-Langevin and Turcotte, 2007). Hybrid bolts are composed of a split set, with a resin rebar installed within the split set. Due to excessive wall deformation, it has been found that the resin rebar needs to be installed at the same time as the split set. The bolts are installed on a $1.4 \times 1.2 \mathrm{~m}$ pattern connected with 0 gauge mesh straps. In particular, the mesh straps are installed to provide additional support to the lower North wall and the upper South wall of footwall development, where most deformation and past rockburst damage has been observed. The hybrid bolt system has performed well during a number of recent large seismic events and is currently used in areas of greater seismic risk throughout the mine.

\subsubsection{Exclusion procedures}

At LaRonde, stress change from final stope blasting can result in significant levels of seismic activity with the potential for rock mass deterioration and eventually rockfalls. A re-entry protocol has been established to restrict access to specific areas that may experience high levels of seismicity and related ground control hazards. The protocol is enforced in certain parts of the mine, depending on blast type and blast size (Table 1).

This protocol has been developed based on 4 years of experience with seismicity following stope blasts. 
Table 1 Re-entry protocol at LaRonde

\begin{tabular}{|c|c|c|c|c|c|c|}
\hline & Orebody & Area & Stope & Type of Blast & Tonnes of Ore & Verdict \\
\hline \multirow{9}{*}{$\begin{array}{l}\text { Production } \\
\text { Blast }\end{array}$} & \multirow{2}{*}{7} & \multirow{2}{*}{ All } & \multirow{2}{*}{ All } & \multirow{2}{*}{ All } & 3000 or less & No protocol \\
\hline & & & & & More than 3000 & Protocol used \\
\hline & \multirow{7}{*}{20} & $\begin{array}{l}\text { West abutment } \\
215 \mathrm{~L} \text { and } 224 \mathrm{~L}\end{array}$ & All & All & All & No protocol \\
\hline & & \multirow{6}{*}{ All other areas } & \multirow{3}{*}{$\begin{array}{l}\text { Primary } \\
\text { Stope }\end{array}$} & \multirow{2}{*}{ Initial blast } & 5000 or less & No protocol \\
\hline & & & & & More than 5000 & Protocol used \\
\hline & & & & Final blast & All & Protocol used \\
\hline & & & \multirow{3}{*}{$\begin{array}{l}\text { Secondary } \\
\text { Stope }\end{array}$} & \multirow{2}{*}{ Initial blast } & 15000 or less & No protocol \\
\hline & & & & & More than 15000 & Protocol used \\
\hline & & & & Final blast & All & Protocol used \\
\hline
\end{tabular}

Table 2 shows the minimum duration of the Restricted Access Protocol, also depending on the orebody and stope type.

Table 2 Duration of the restricted access protocol

\begin{tabular}{ccc}
\hline Orebody & Stope & Minimum Time \\
\hline 7 & All & 6 hours \\
\hline \multirow{2}{*}{20} & Primary & 9 hours \\
\cline { 2 - 3 } & Secondary & 8 hours \\
\hline
\end{tabular}

Seismicity occurs in a well-defined failure band around the stoping block. The consistency of seismicity within the failure band allows identification of development excavations which need to be closed during stope blasting.

Table 3 gives general rules for which development needs to be closed.

Table 3 Location of development closed during stope blasting

\begin{tabular}{|c|c|c|c|}
\hline Orebody & Stope & Region & Minimum Zone of Closure \\
\hline \multirow{4}{*}{7} & \multirow{4}{*}{ All } & \multirow{3}{*}{ Normal } & 1) Zone of stress change on the bottom level of the stope \\
\hline & & & 2) Zone of stress change on the top level of the stope \\
\hline & & & 3) Zone of stress change on the level above the stope \\
\hline & & Sill pillar & $\begin{array}{l}\text { Minimum zone of closure is defined by the highest } \\
\text { excavation that can be affected by stress change }\end{array}$ \\
\hline \multirow{7}{*}{20} & \multirow{4}{*}{ Primary } & \multirow{3}{*}{ Normal } & 1) Zone of stress change on the bottom level of the stope \\
\hline & & & 2) Zone of stress change on the top level of the stope \\
\hline & & & 3) Zone of stress change on the level above the stope \\
\hline & & Sill pillar & $\begin{array}{l}\text { Minimum zone of closure is defined by the highest } \\
\text { excavation that can be affected by stress change }\end{array}$ \\
\hline & \multirow{3}{*}{ Secondary } & \multirow{3}{*}{ All } & 1) Zone of stress change on the bottom level of the stope \\
\hline & & & 2) Zone of stress change on the top level of the stope \\
\hline & & & 3) Zone of stress change on the level above the stope \\
\hline
\end{tabular}


Using these rules, a closure note is written for each blast, specifying which development excavations are closed, and for what period of time. Re-opening of restricted areas is only permitted when seismic activity has returned to normal levels and the restricted areas have been inspected by a supervisor or a member of the technical services group to ensure that there are no potentially dangerous ground conditions.

It is important to note that the Restricted Entry Protocol, the duration of closure, and the zones to be closed are only guidelines, and can be modified based on local conditions such as geology, mining sequence or any other factor that may influence stress redistribution.

When abnormal seismic activity is identified around development headings, a Restricted Access Protocol may also be enforced. The duration of the restricted access and headings affected are determined by local conditions.

The occurrence of a significant seismic event can also initiate a restricted access procedure. The mine control room, which is staffed 24 hours a day, has access to the seismic system data. If a significant event is reported in the mine, the control room operator checks the seismic data for the location and magnitude of the event. If a seismic event of local magnitude -0.8 or larger occurs in the mine within 20 metres of mine development, or if the control room operator deems the seismicity abnormal, the "LaRonde Workplace Closure Procedure" is initiated. In this procedure, mine development on the level above and below the event, within 60 metres of the location of the event, are closed for a period of 12 hours. At the end of the closure period, or on advice from Engineering Technical Services, a supervisor inspection of the workplace is conducted. If there is no observable damage in the workplace, it is re-opened to mine operations activities. If there is damage in the workplace, it remains closed until an inspection from Engineering Technical Services. All instances of the LaRonde Workplace Closure procedure are reported to the Safety Department, recorded in the Ground Control Log Book and are clearly posted on the Underground Noticeboard.

\subsubsection{Changes in workplace practices}

One of the main changes in workplace practices was introduced soon after the commissioning of the seismic system, when a real-time interface with the seismic system was installed in the control room. Most underground workers are in constant radio contact with the control room operator. Through this link they are informed in near real-time of the location and magnitude of any seismic events that they may have heard or felt. This information eliminated most of the uncertainty and anxiety that had been associated with seismicity at the mine.

The second adjustment in workplace practices was to ensure that any person working in seismically active ground conditions, who did not feel comfortable with the level of seismic activity, pulled out of the workplace. The rationale behind this measure is that a worker who is distracted by his surroundings does not fully concentrate on his task, and has a much greater chance of having an accident.

\subsubsection{Workforce training}

Seismicity is an integral part of all ground control training programs at LaRonde. It is initially described on the very first day for any worker undertaking their mine induction. Furthermore, dynamic resistant support, and how it is used at LaRonde, is described in detail in the ground support training program. Supervisors are also given a rock support quality control training program that describes, among other things, seismicity and dynamic resistant support.

With the recent introduction of the SRMP, a specific training program regarding working safely in active ground conditions (adapted from ACG, 2000) is now given to all underground personnel. This detailed training program explains the signs of active ground conditions, what causes active ground conditions, and describes how to work safely in active ground conditions.

\subsection{Communication tools}

Even the best seismic risk management techniques will fall short without adequate communication. As such, it is imperative that bi-directional communication tools be implemented in order to make the most of all the information that is available at the mine. 


\subsubsection{Ground control log book}

In Quebec mines, it is required that a Ground Control Log Book be made available to underground personnel, so that any unusual occurrence pertaining to rock mechanics and ground control can be communicated to all personnel. All entries have to be addressed by a member of the ground control department. This very useful tool ensures that a bi-directional exchange of information is established between the underground personnel, supervision and engineering.

At LaRonde, rock noise, rockburst damage and any other information pertaining to seismicity as it is witnessed underground is first reported in the Ground Control Log Book.

\subsubsection{Rock noise reports}

All seismic events reported in the Ground Control Log Book are individually processed by ground control personnel and are the subject of a rock noise report. This report summarises key information such as the date and time at which the event occurred and its location and magnitude in the form of a very simple single-sheet table. The location of the event relative to nearby excavations is also provided on mine plans, in which the event is typically illustrated in plan and longitudinal view.

These reports are made available to all. They are greatly appreciated by the workforce, as they provide visual and factual data on something that is, from their perspective, invisible and intangible. It is a transparent tool that helps demystify seismicity.

\subsubsection{Monthly report}

At the end of the month, a report summarising seismicity is generated by the ground control team. This report contains information about:

- Concentration of general seismicity in the mine (longitudinal view).

- Concentration of large events in the mine (longitudinal view).

- Magnitude-time graph (1 month) identifying "abnormal" trends in seismicity (normally associated with stope blasts).

- Magnitude-time graph (1 year) identifying "abnormal" trends in seismicity (normally associated with large-scale structures/configurations).

- Important facts during the month (damaging events, emergence of new clusters of events, spikes in activity and inferred causes).

- Detailed seismic risk analysis of mine workings (MS-RAP) and repercussions on production.

- Any other relevant information.

This report is kept as short and to the point as possible. It is primarily aimed at mine planners and upper supervision (mine captains) so that they can base their planning decisions on the best available information. It also illustrates very clearly the effect of mine planning and mine operations on seismicity in the mine.

\subsubsection{Special meetings/others}

Occasionally other communication means such as special meetings are used to provide information to the workforce and to allow them to give feedback. Historically at LaRonde, special meetings have been held when major rockbursts occurred. However, such meetings are to be held for any situation that warrants it.

\section{Additional notes}

It is felt that the creation of a rockburst database should be the very first step in the development of a SRMP. For LaRonde, it provided invaluable insight into the mechanisms and the underlying causes of rockbursting at the mine and that this knowledge guided the content of the rest of the document to a great extent.

In order to ensure that the rationale behind the current instalment of the measures outlined in the SRMP is not lost, it is particularly important that all changes to the various procedures be tracked and listed in the 
document itself. At LaRonde, a table is added to each section. This table lists all the publications that had an effect on the current version of the associated procedure. The effective date and a general description of the change that is being introduced are also provided.

\section{Conclusions}

Agnico-Eagle is dedicated to the highest standards of health and safety. For more than 10 years, LaRonde mine has been rated among the safest of the many mines in Quebec, with a combined accident frequency index below the provincial mining industry average. In July 2007, the underground operation attained 1,000,000 hours (over 850 days) without compensable accident.

The mine takes pride in its proactive safety programs and procedures that prepare people for any eventuality and operate 24 hours a day, seven days a week. Furthermore, the 24 volunteers who make up the first-rate mine rescue team embody the idea that Agnico-Eagle people are always watching out for one another - and for people in other mines as well. The mine rescue team recently won its third consecutive Quebec championship, a first since the creation of the event.

More than 30,000 events have been recorded at the mine over four years of seismic monitoring. Of these events, less than 20 caused damage to excavations, and of those, none caused any injuries. These numbers are a testament to the proactive measures that have been implemented over time. The development and implementation of the "Seismic Risk Management Plan" at LaRonde represents yet another step towards making the mine an ever safer place to work.

\section{References}

ACG (2000) Working Safely in Active Ground Conditions. Australian Centre for Geomechanics, Mine Seismicity and Rockburst Risk Management Project Training Presentation.

Agnico-Eagle (2007) Agnico-Eagle Reports Strong Quarterly Earnings and Record Cash Flows; $19 \%$ Increase in Gold Reserves to Record Level., Press Release, Available from <www.agnico-eagle.com>, February 21, 2007.

Andrieux, P. and Hadjigeorgiou, J. (2006) External Review of the 1 April 2006 Rockburst in the 164-20-W at LaRonde Mine. Technical memorandum, Itasca Consulting Canada Inc. and Georock Inc., $17 \mathrm{p}$.

Heal, D., Potvin, Y. and Hudyma, M. (2006) Evaluating Rockburst Damage Potential in Underground Mining, Proceedings $41^{\text {st }}$ Symp. On Rock Mechanics, June 17-21 2006, Golden, Colorado.

Hudyma, M. and Brummer, R.K. (2006) Mining Induced Seismicity Review - Agnico-Eagle Mines Limited. Technical memorandum (Itasca Consulting Canada Inc.), $196 \mathrm{p}$.

Hudyma, M. (2007) Review of Seismic Events of December 11th, 2006 and January 11 ${ }^{\text {th }}, 2007$ on 224L at LaRonde Mine, Technical memorandum (Itasca Consulting Canada Inc.), $61 \mathrm{p}$.

Mercier-Langevin, F. and Turcotte, P. (2007) Evolution of Ground Support Practices at Agnico-Eagle's LaRonde Division - Innovative Solutions to High Stress Yielding Ground,. Proceedings $1{ }^{\text {st }}$ Canada-US Rock Mechanics Symposium., May 27-31 2007, Vancouver, Canada.

Mercier-Langevin, F. (2006) Événement sismique avec projection 164-20-W. Internal technical memorandum, Engineering Department, LaRonde Division, $19 \mathrm{p}$.

Simser, B., Andrieux, P., Mercier-Langevin, F., Parrott, T. and Turcotte, P. (2006) Field behaviour and Failure Modes of Modified Conebolts at the Craig, LaRonde and Brunswick Mines in Canada. Proceedings $3^{\text {rd }}$ International Seminar on Deep and High Stress Mining, October 2-4 2006, Quebec City, Canada. 